\title{
Phenotypic Analysis for a Cell Line of Canine Epidermal Keratinocytes
}

\author{
Sanae SHIBATA ${ }^{1)}$, Sadatoshi MAEDA ${ }^{2) *}$, Hiromi TSUCHIDA ${ }^{2)}$ and Tsuneo FUKATA ${ }^{1)}$ \\ ${ }^{1)}$ The United Graduate School of Veterinary Sciences and ${ }^{2)}$ Department of Veterinary Internal Medicine, Faculty of Applied Biological \\ Sciences, Gifu University, 1-1 Yanagido, Gifu 501-1193, Japan
}

(Received 19 March 2008/Accepted 20 April 2008)

\begin{abstract}
Epidermal keratinocytes have the potential to produce inflammatory mediators that are considered to play an important role in skin diseases such as atopic dermatitis (AD). Thus, cell lines of canine epidermal keratinocytes are useful for studying the biological reactivity of keratinocytes in vitro. However, there has been no report on properly analyzing the phenotype of canine keratinocyte cell lines. In this work, we performed phenotypic analysis of CPEK, which was derived from the epidermis of an adult dog in order to examine the phenotypic similarity with epidermal keratinocytes. The present findings indicated that CPEK cells expressed markers for epidermal keratinocytes including cytokeratin $14, \alpha_{6}$ integrin and PCNA. Our findings demonstrated that CPEK could be a useful cell line for investigating the central role of epidermal keratinocytes in the pathogenesis of $\mathrm{AD}$ in vitro.
\end{abstract}

KEY WORDS: cytokeratin, integrin, keratinocytes.

Atopic dermatitis (AD) is one of the most common skin diseases in dogs and is associated with type I hypersensitivity. Previous studies have reported that the thymus and activation-regulated chemokine (TARC/CCL17) is strongly expressed in lesional skin of humans [12] and dogs [10] with AD. Thus, CCL17 is thought to participate in the pathogenesis of canine AD. Recent studies have demonstrated that basal keratinocytes may be a major cell source for CCL17 production in dogs [10]. However, induction factors for CCL17 production in keratinocytes have not been identified because an appropriate canine cell line has not been available. To date, one keratinocyte cell line, CPEK (CELLnTEC Advanced Cell Systems, Switzerland) is commercially available for veterinary research. CPEK was derived from the epidermis of an adult Beagle dog. However, phenotypic analysis of CPEK has not previously been conducted. In the present study, to determine the possibility of CPEK as a model for canine skin-derived basal keratinocytes, we immunohistochemically investigated the phenotype of CPEK using proliferative and differential markers.

A cell line of canine epidermal keratinocyte, CPEK cells were purchased from CELLnTEC Advanced Cell Systems. Fifth- to tenth-passage cells were used for experiments. The cells were initially cultured in $75 \mathrm{~cm}^{2}$ flasks (NUNC, Denmark) in $10 \mathrm{ml}$ complete CnT-09 (CELLnTEC) until approximately $80 \%$ confluence at $37^{\circ} \mathrm{C}$ under $5 \% \mathrm{CO}_{2}$. For subculture, the cells were rinsed with $10 \mathrm{~m} l$ Versene 1:5,000 (Invitrogen Corporation, U.S.A.) and trypsinized by the addition of $2 \mathrm{~m} l$ of TrypLE Express (Invitrogen) followed by incubation at $37^{\circ} \mathrm{C}$ for $5-10 \mathrm{~min}$. The cell suspension was transferred to a sterile $15 \mathrm{~m} l$ centrifuge tube and centrifuged at $180 \times g$ for $5 \mathrm{~min}$ at room temperature. The cell pellet was gently re-suspended in CnT-09 and transferred to

\footnotetext{
* Correspondence to: Maeda, S., Department of Veterinary Internal Medicine, Faculty of Applied Biological Sciences, Gifu University, 1-1 Yanagido, Gifu 501-1193, Japan.

e-mail: sadat@gifu-u.ac.jp
}

$75 \mathrm{~cm}^{2}$ flasks at a density of approximately $2 \times 10^{4} / \mathrm{cm}^{2}$ for subculture.

To establish a growth curve, CPEK was seeded to 6-well plates in $2 \mathrm{~m} l \mathrm{CnT}-09$. On days 1, 2, 3, 5 and 7, the cells were harvested for cell counting by a hemocytometer. Viability was confirmed by the trypan blue exclusion method. This experiment was replicated three times. The results were plotted semilogarithmically in order to determine population doubling time by saturation density. The population doubling time was $14.8 \pm 1.50 \mathrm{hr}$, and the saturation density was $23.3 \times 10^{4} \pm 2.49$ cells $/ \mathrm{cm}^{2}$ when the initial cell density was adjusted to $1 \times 10^{4}$ cells $/ \mathrm{cm}^{2}$.

For morphological and immunohistochemical analyses, CPEK was plated at $2 \times 10^{4} / \mathrm{cm}^{2}$ in a total volume of $1 \mathrm{ml} /$ chamber of CnT-09 in 4-chamber glass culture slides (BD Biosciences, U.S.A.). When CPEK reached $80 \%$ confluency, the cells were fixed with $99 \%$ methanol and permeabilized with $0.5 \%$ Triton ${ }^{\circledR} \mathrm{X}-100$ in PBS followed by blocking with $10 \%$ goat serum for $30 \mathrm{~min}$. The cells were incubated with anti-human Proliferating Cell Nuclear Antigen (PCNA, monoclonal, 1:50 dilution, DakoCytomation, Denmark) [3], mouse anti-human cytokeratin 14 (monoclonal, 1:5 dilution, PROGEN, Germany) [14] and anti-human cytokeratin 10 (monoclonal, 1:100 dilution, Abcam, UK) [14] for $1 \mathrm{hr}$. Mouse $\operatorname{IgG}_{1}$ (1:100 dilution, Ancell Corporation, U.S.A.) and mouse $\operatorname{IgG}_{2 \mathrm{a}}(1: 100$ dilution, $\mathrm{BD})$ were used as isotype controls. For secondary antibodies, rat anti-mouse $\mathrm{IgG}_{1}$ FITC conjugate (1:200 dilution, BD) for anti-cytokeratin 14 and 10 , rat anti-mouse $\operatorname{IgG}_{2 \mathrm{a}}$ RITC conjugate (1:100 dilution, Santa Cruz Biotechnology, Santa Cruz, U.S.A.) for anti-PCNA were used. DAPI (1:500 dilution, Dojindo Laboratories, Japan) was used for nucleus counterstaining at the same time. The morphology of the cells under phase contrast microscopy demonstrated the classical cobbled appearance of undifferentiated keratinocytes (Fig. 1A). Immunohistochemical study indicated that CPEK was positive for cytokeratin 14 (Fig. 1B) but negative for cytokeratin 

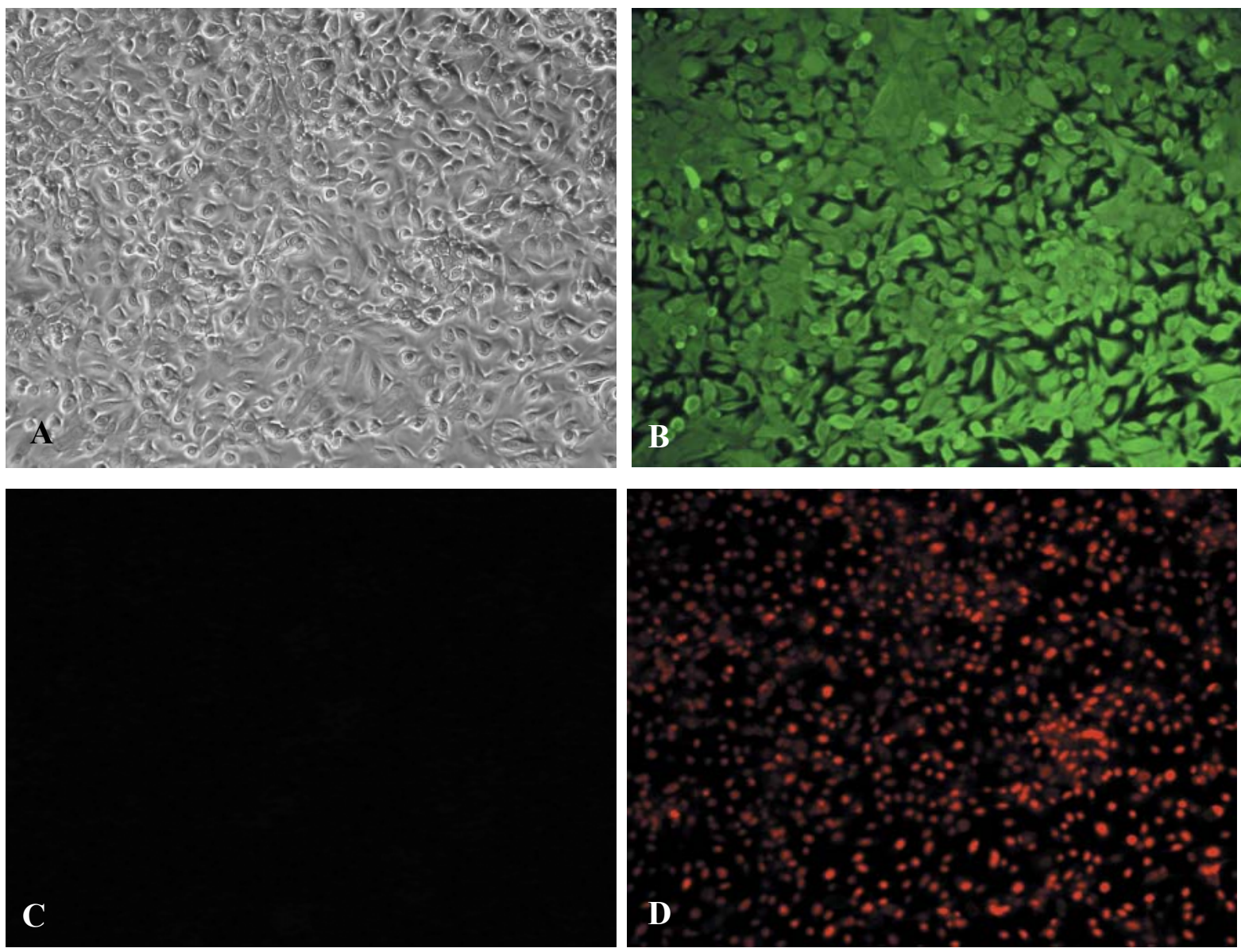

Fig. 1. Morphological and immunohistochemical findings of CPEK cells. A: bright field, B: Cytokeratin 14, C: Cytokeratin 10, D: Proliferating cell nuclear antigen $(200 \times)$.

10 (Fig. 1C). All cells were stained with anti-PCNA, demonstrating active proliferation of these cells (Fig. 1D).

For flowcytometric analysis (FACS Calibur $\left.{ }^{\mathrm{TM}}, \mathrm{BD}\right)$, CPEK were rinsed using Versene 1:5000 and trypsinized by TrypLE Express in order to harvest the cells. The cells were incubated with either rat anti-human integrin alpha $6\left(\alpha_{6}\right.$ integrin, monoclonal, 1:100 dilution, Chemicon, U.S.A.) [15] or rat $\operatorname{IgG}_{2 \mathrm{a}}(1: 100$ dilution, $\mathrm{BD})$ as isotype control for $30 \mathrm{~min}$, followed by incubation with FITC conjugatedmouse anti-rat $\operatorname{IgG}_{2 \mathrm{a}}(1: 100$ dilution, BD) secondary antibody for $30 \mathrm{~min}$. To quantify the expression of $\alpha_{6}$ integrin, mean fluorescence intensity was calculated by a analyzing software (CellQuest $\left.{ }^{\mathrm{TM}}, \mathrm{BD}\right)$. Flowcytometric analysis showed that $99.96 \%$ of CPEK were positive for $\alpha_{6}$ integrin (Fig. 2).

Although basal keratinocytes may be a major cell source for CCL17 production in dogs, in vitro study using canine keratinocytes has not been performed. Canine epidermal keratinocytes, CPEK could be used as an in vitro experimental system for studying biological reactivity in response to allergic inflammatory stimuli. Thus, this study investigated whether CPEK would be suitable for research on

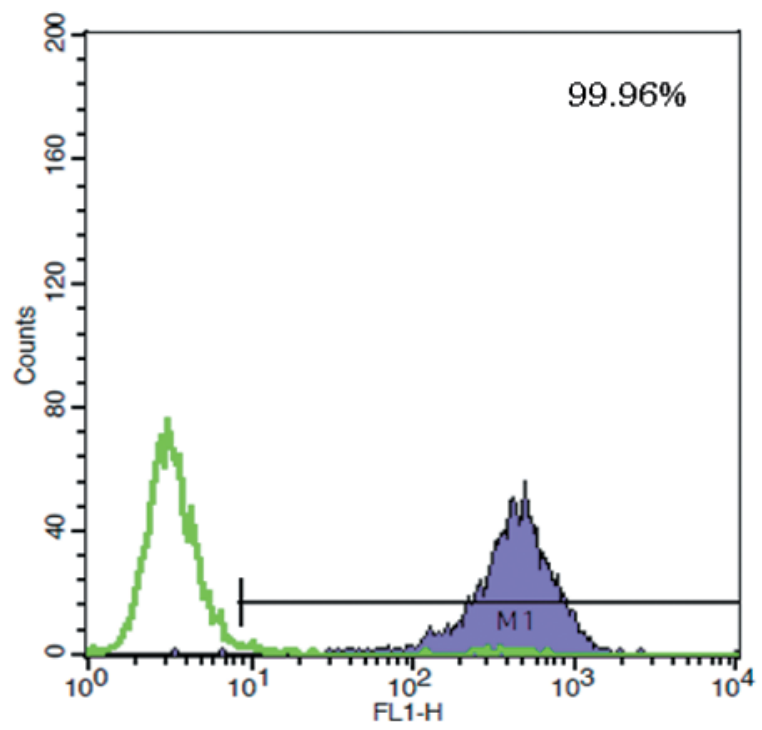

Fig. 2. Flow cytometric detection of $\alpha_{6}$ integrin. The histogram shows the staining intensity of isotype (green) and $\alpha_{6}$ integrin (purple) monoclonal antibodies. 
canine skin diseases.

Cytokeratin 10 and 14 are known as differential markers of epithelial cells. Keratinocytes in the basal layer express cytokeratin 14, but this expression is down-regulated during differentiation, switching to cytokeratin 10 as keratinocytes move into suprabasal layers [7]. The proliferation marker, PCNA identifies a proliferating subpopulation of basal keratinocytes [6]. The present study showed that CPEK was positive for cytokeratin 14 and PCNA but negative for cytokeratin 10, demonstrating phenotypic similarity with basal keratinocytes. For additional characterization of CPEK, we also investigated expression of an adhesion molecule, $\alpha_{6}$ integrin, which is exclusively expressed on the epidermal-dermal junction of basal keratinocytes [2, 11, 15]. In basal keratinocytes, flowcytometric analysis could separate two subpopulations into proliferative undifferentiated $\left(\alpha_{6}{ }^{\text {bri }}\right)$ or postmitotic differentiating $\left(\alpha_{6}{ }^{\mathrm{dim}}\right)$ keratinocytes based on expression of $\alpha_{6}$ integrin [9]. In the present study, almost all (99.96\%) CPEK expressed integrin, but the expression pattern was not bimodal. Therefore, the present findings strongly indicate that CPEK has a proliferative undifferentiated phenotype as well as HaCaT cells [1]. Although the profile of cytokines and chemokines production remain unclear in CPEK, basal keratinocytes have been reported to produce numerous inflammatory mediators such as CCL2, CCL5, CCL17 and TNF- $\alpha$ [4, 5, 8, 12, 13, 16]. Thus, further study should aim to examine the similarity in the profile between CPEK and basal keratinocytes. In conclusion, we suggest that CPEK should be a useful cell line for investigating the immunopathogenesis of inflammatory skin diseases.

ACKNOWLEDGEMENTS. This study was supported by a Grant-in-Aid for Scientific Research and for JSPS Fellows from the Ministry of Education, Science, Sports and Culture, and Special Coordination Funds for Promoting Science and Technology of the Science and Technology Agency of the Japanese Government.

\section{REFERENCES}

1. Boukamp, P., Breitkruetz, D., Hulsen, A., Tomakidi, P., Fusenig, N. 1994. pp. 485-499. In vitro transformation and fumor progression: a multistep model for skin carcinogenisis. In: The keratinocyte Handbook. (Leigh I, L. B., Watt F ed.), Cambridge University Press, Cambridge.

2. Carter, W. G., Kaur, P., Gil, S. G., Gahr, P. J. and Wayner, E. A. 1990. Distinct functions for integrins alpha 3 beta 1 in focal adhesions and alpha 6 beta 4/bullous pemphigoid antigen in a new stable anchoring contact (SAC) of keratinocytes: relation to hemidesmosomes. J. Cell. Biol. 111: 3141-3154.

3. Galkowska, H., Waldemar, L. O. and Wojewodzka, U. 1996. Reactivity of antibodies directed against human antigens with surface markers on canine leukocytes. Vet. Immunol. Immunopathol. 53: 329-334.

4. Giustizieri, M. L., Mascia, F., Frezzolini, A., De Pita, O., Chinni, L. M., Giannetti, A., Girolomoni, G. and Pastore, S.
2001. Keratinocytes from patients with atopic dermatitis and psoriasis show a distinct chemokine production profile in response to T cell-derived cytokines. J. Allergy. Clin. Immunol. 107: 871-877.

5. Goebeler, M., Trautmann, A., Voss, A., Brocker, E. V., Toksoy, A. and Gillitzer, R. 2001. Differential and sequential expression of multiple chemokines during elicitation of allergic contact hypersensitivity. Am. J. Pathol. 158: 431-440.

6. Greig, A. V., Linge, C., Cambrey, A. and Burnstock, G. 2003. Purinergic receptors are part of a signaling system for keratinocyte proliferation, differentiation, and apoptosis in human fetal epidermis. J. Invest. Dermatol. 121: 1145-1149.

7. Hudson, D. L. 2002. pp. 157-167. Keratins as Markers of Epithelial Cells. In: Epithelial Cell Culture Protocols. (Wise, C. ed.), Humana Press, Totowa.

8. Khan, A., Farah, C. S., Savage, N. W., Walsh, L. J., Harbrow, D. J. and Sugerman, P. B. 2003. Th1 cytokines in oral lichen planus. J. Oral. Pathol. Med. 32: 77-83.

9. Li, A., Simmons, P. J. and Kaur, P. 1998. Identification and isolation of candidate human keratinocyte stem cells based on cell surface phenotype. Proc. Natl. Acad. Sci. U.S.A. 95: 39023907.

10. Maeda, S., Tsukui, T., Saze, K., Masuda, K., Ohno, K., Tsujimoto, H. and Iwabuchi, S. 2005. Production of a monoclonal antibody to canine thymus and activation-regulated chemokine (TARC) and detection of TARC in lesional skin from dogs with atopic dermatitis. Vet. Immunol. Immunopathol. 103: 83-92.

11. Sonnenberg, A., Calafat, J., Janssen, H., Daams, H., van der Raaij-Helmer, L. M., Falcioni, R., Kennel, S. J., Aplin, J. D., Baker, J., Loizidou, M. and et al. 1991. Integrin alpha 6/beta 4 complex is located in hemidesmosomes, suggesting a major role in epidermal cell-basement membrane adhesion. J. Cell. Biol. 113: 907-917.

12. Vestergaard, C., Bang, K., Gesser, B., Yoneyama, H., Matsushima, K. and Larsen, C. G. 2000. A Th2 chemokine, TARC, produced by keratinocytes may recruit CLA+CCR4+ lymphocytes into lesional atopic dermatitis skin. J. Invest. Dermatol. 115: 640-646.

13. Vestergaard, C., Yoneyama, H., Murai, M., Nakamura, K., Tamaki, K., Terashima, Y., Imai, T., Yoshie, O., Irimura, T., Mizutani, H. and Matsushima, K. 1999. Overproduction of Th2-specific chemokines in NC/Nga mice exhibiting atopic dermatitis-like lesions. J. Clin. Invest. 104: 1097-1105.

14. Vos, J. H., van den Ingh, T. S., Misdorp, W., Molenbeek, R. F., van Mil, F. N., Rutteman, G. R., Ivanyi, D. and Ramaekers, F. C. 1993. Immunohistochemistry with keratin, vimentin, desmin, and alpha-smooth muscle actin monoclonal antibodies in canine mammary gland: benign mammary tumours and duct ectasias. Vet. Q. 15: 89-95.

15. Yamazoe, K., Miyamoto, S., Hikosaka, Y., Kitagawa, K., Watanabe, K., Sakai, H. and Kudo, T. 2007. Three-dimensional culture of keratinocytes and the formation of basement membrane for canine footpad substitute. J. Vet. Med. Sci. 69: 611-617.

16. Zheng, X., Nakamura, K., Furukawa, H., Nishibu, A., Takahashi, M., Tojo, M., Kaneko, F., Kakinuma, T. and Tamaki, K. 2003. Demonstration of TARC and CCR4 mRNA expression and distribution using in situ RT-PCR in the lesional skin of atopic dermatitis. J. Dermatol. 30: 26-32. 